\title{
Contribution for increasing the manufacturing companies productivity using a tracking and planning production program
}

\author{
Iaroslav Francisc Pișec ${ }^{1, *}$, and Alin Pop ${ }^{1}$ \\ ${ }^{1}$ University of Oradea, Department of Industrial Engineering, Universităţii 1, Oradea, România
}

\begin{abstract}
In this paper is presented roughly a tracking and planning production program. The major challenge for manufacturing companies is to have the highest efficiency regarding the productivity. For this reason, the best way to achieve this is to track all elements from production process and to plan all phases as well as possible. The method used for planning production, is the Critical Path Method (CPM) because this kind of planning method determinates in advance the time of fabrications of complex parts. Using this tracking and planning production program, the companies can check the machine tools workload, can analyse the capacity, can assign the proper equipment for part's fabrication, can estimate the delivering products time and also the cost of it. One of the advantages is that this information is provided on real time.
\end{abstract}

\section{Introduction}

In this days, most of the manufacturing companies are involved in a dynamic challenge [1] because the need of a short product and technology life cycle [2] and a high numbers of product variants as the demand for individualized products rises $[2 ; 3]$.

An important obstacle which manufacturing companies have to cross, when is needing to concept a new manufacturing system to produce several products, is the right selection of the optimal quantity and portfolio of product-dedicated and flexible capacities.

Production planning is a time bound activity, in terms of years, months weeks and days. It is an integral part of the companies planning process and depicts the organization planning process [4].

The support activities of the tracking and planning production program can be broken roughly into three-time horizons: long term, medium term, and short term.

In the long term, the system is responsible for providing information to make decisions on the appropriate amount of capacity (including equipment, buildings, suppliers, and so forth) to meet the market demands of the future.

In the intermediate term, the fundamental issue addressed by the tracking and planning production program is matching supply and demand in terms of both volume and product mix. Although this is also true in the longer term, in the intermediate term, the focus is more on providing the exact material and production capacity needed to meet customer needs. This means planning for the right quantities of material to arrive at the right time and place to support product production and distribution.

In the short term, detailed scheduling of resources is required to meet production requirements. This involves time, people, material, equipment, and facilities. Key to this activity is people working on the right things. As the day-to-day activities continue, the tracking and planning production program must track the use of resources and execution results to report on material consumption, labour utilization, equipment utilization, completion of customer orders, and other important measures of manufacturing performance.

Moreover, as customers change their minds, things go wrong, and other changes occur, the tracking and planning production program must provide the information to managers, customers, and suppliers on what happened, provide problem-solving support, and report on the resolution of the problems. Throughout this process, communication with customers on production status and changes in expectations must be maintained.

The specific requirements for the tracking and planning production program design depend on the nature of the production process, the degree of supply chain integration, customers' expectations, and the needs of management. As the program is required to integrate with other company systems in the supply chain and/or with the tracking and planning production programs of the firm, additional design parameters are introduced. Moreover, these tracking and planning production program requirements are not static. As competitive conditions, customer expectations, supplier capabilities, and internal needs change, the tracking and planning production program needs to change.

\section{The need of creating a tracking and planning production program}

In order to manage the production process easily and efficiently, it is necessary to implement a program that closely follows all the elements that make up the process. It is built on rigorous methodology and intends to bring

* Corresponding author: pisec.iaroslav@gmail.com 
together all available resources within the company to make the product as efficient as possible.

Getting real-time information (even on-line) for all areas of the company determines maximum control, which reduces the risk of the occurrence of some disturbing factors.

First, the program is used to assign a machine tool which will perform the mechanical processing. Each production part passes through at least two machining operations, cutting the blank and machining, drilling or turning. In this way, it will be assigned a cutting machine and a milling machine. Some parts, such as BLOCK LOCATOR, also have electro-erosion machining, and PIN parts have a grinding process. These mechanical processes will be assigned to specific machines.

Assignment to a machine tool is required for generating the $\mathrm{CNC}$ program. This differ depending on the machine's working parameters, the tools available in the machine's storage tool, fixing devices, etc. It is not possible to assign a machine tool that is in reparation or maintenance because the processing time adds the waiting time until the machine can be used again.

The next step, after the machine is assigned, is to generate the CNC program. Once generated, it is transferred online, and the processing process starts.

The tracking and planning production program manages the machine tools activity, the parts processing part stages. An important aspect of this program is the ability to stop a machining process caused by the modification of the 3D model of the part. It is possible for the part to suffer shape changes in the design phase even at the time of its machining. The machining process is stopped, is checked the stage where the blank is and if it is possible to insert the changes into the actual piece, the CNC program is changed.

Improving the efficiency of the machining department, cost reduction and process assignment, continuous control over the entire activity, real-time analyses and reports are some of the benefits of implementing the tracking and planning production program.

\section{The method used by production planning program}

The method used for planning production, is the Critical Path Method (CPM) because this kind of planning method determinates in advance the time of fabrications of complex parts.

The principle of critical path analysis is to divide a project (complex actions) into component parts at a level that allows for their logical and technological correlation, that is, to make it possible to establish interactions between the component parts. These components are the activities of complex actions.

When defining the list of activities, the specialist involved in this operation uses his experience to answer, for each activity, the following questions:

"What other activities do or necessarily precede this activity?";

"What is the duration of the activity?".
The CPM method is a critical path analysis process in which the only parameter analysed is the time and the representation of the network graph takes into account the following conventions:

- each activity is associated with an orientated segment

- $\quad$ called the arc, defined by its ends, each activity being identified by a spring;

- $\quad$ each arc is associated with a value equal to the duration of the activity it represents;

- the conditioning of two activities is represented by the succession of two arcs.

Bellow is an example of how the CPM method works.

If two or more activities have the same precedent activity, for example A precedes B and A precedes C, the representation in the network graph will take the form of Figure 1 (a). Arcs B and C symbolize two activities that can only begin after activity A is completed. Activities B and $\mathrm{C}$ can be executed simultaneously. Also, the execution of an activity may depend on the completion of several previous direct activities, for example A precedes $\mathrm{C}$ and $\mathrm{B}$ precedes $\mathrm{C}$ as in Figure 1 (b). In this situation, activity $\mathrm{C}$ cannot begin, logically, until $\mathrm{A}$ and $\mathrm{B}$ have finished.

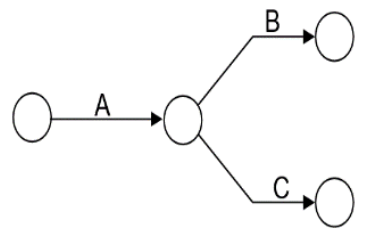

(a)

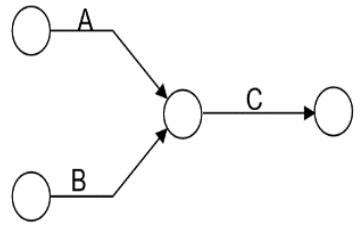

(b)
Fig. 1. Examples of network graph

The most important values to be computed after the network has been traced are:

- the earliest start time of an event - is the closest (time) moment at which a node can be reached;

- the latest moment of realization of an event - is the

most remote (time) moment at which a node must be reached for the project to finish on the set date.

Among the advantages of the CPM method (and in general the critical path analysis) we highlight:

- anticipating the execution time of the complex projects;

- during the running of the project allows for permanent control of its execution;

- explaining the logical and technological links between activities;

- highlighting critical activities;

- highlighting non-critical activities, which have time reserves;

- allows periodic updates to be made without redoing the graph;

- offers the possibility to carry out calculations to optimize the duration of a project, based on the cost criterion;

- represents a streamlined and rational method that allows timely programming of activities considering resources. 


\section{Input data / Output data}

The operation of the program for tracking and planning the production requires the introduction in good conditions of the input data as can be seen in the figure below.

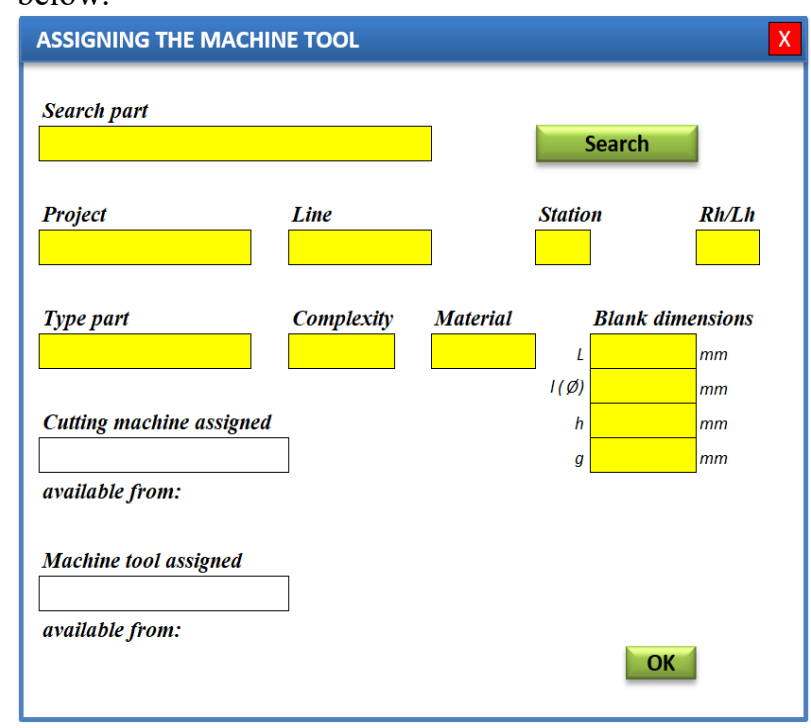

Fig. 2. Entering part details for machine tool assignment

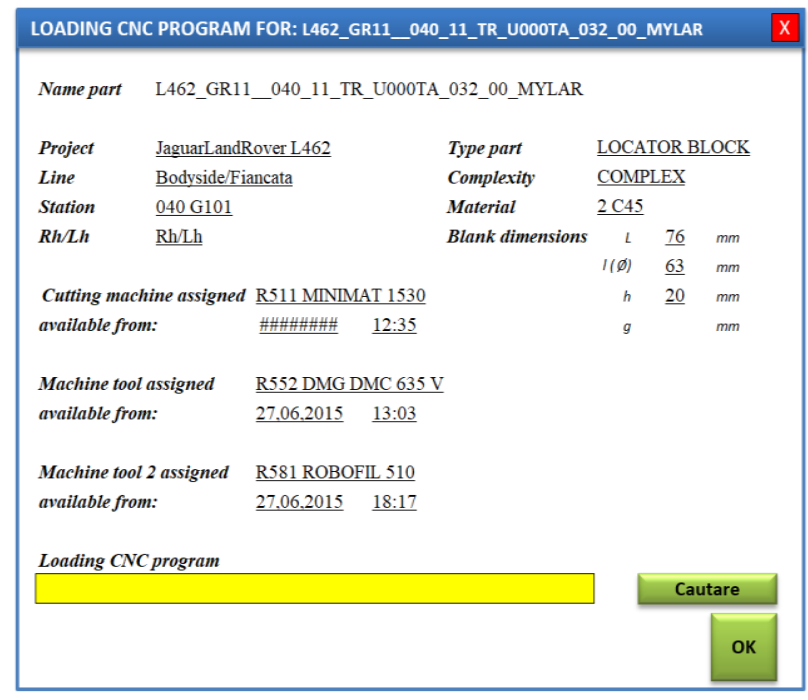

Fig. 3. Loading the CNC program for the given part

In Figure 2, it can be seen with yellow colour, which part information should be entered for assignment of the machine tool. The first step involves loading the 3D model of the part into the program. In this way is named also the part, the name which will be used in the program. Some inputs are just to know the system from which the part is part of (project, line, station). The "Rh / Lh" box determines the amount of pieces needed to be manufactured. For example, if "Rh" or "Lh" is selected, only one piece will be processed. If " $\mathrm{Rh} / \mathrm{Lh}$ " is selected then two pieces will be processed, one of them will be symmetrical, and if "Rh=Lh" is selected then two identical pieces will be processed.

The type of part and its complexity is the main factor in the assignment of the machines tool. Below is a table in which is showed the predefined assignment of existing machine tools to processing different parts.

Table 1. Predefined assignment of machine tools to different parts

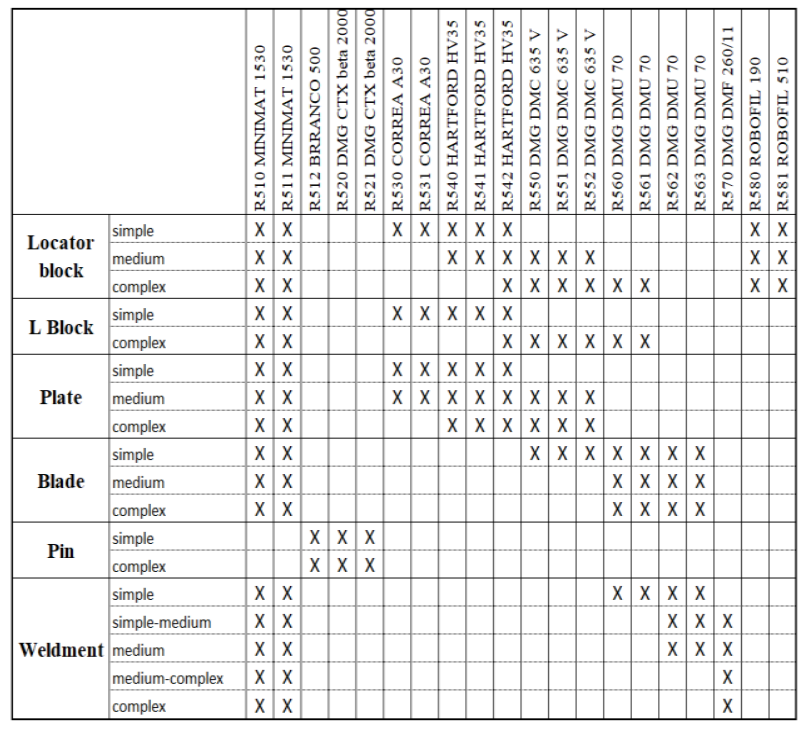

The reports about machine tools, about the parts processed or which will be processed are the output data of the program for tracking and planning production. They can be saved as files in Microsoft Office Excel format or can be viewed online within the program.

After loading the CNC program, it is automatically transferred to the machine tools assigned via the digital data management system, Product Life Management (PLM). The PLM system is primarily a database of all the information about the projects that a company have realized or is realizing it.

Other outputs are:

- the actual start date of each operation;

- the actual end date of each operation;

- the duration of the operation in the programming process (i.e., operational or non-operational time);

- the gap between each operation and its starting date

at the latest;

- delaying the execution of the production task with its starting date at the latest.

The generation of reports can be determined by their own information and control requirements or can be set as follows:

- daily reports;

- monthly reports;

- quarterly reports;

- annual reports.

These reports can be used to calculate the cost of mechanical processing, to calculate machine tool efficiency, to calculate service life, etc.

Based on the reports, it can be found whether a machine tool does not work at full capacity due to the small number of machined parts. Then it must be equipped with tools and devices suitable for the processing of other types of parts. It is important that the machine tool does not have a rest time because it is a disadvantage in the production efficiency. 


\section{Presentation of the functioning and usage of the program}

The tracking and planning production works well and generates accurate information with the condition that it is used correctly. That is why the operator of this program should be trained and then supervised for a determined period of time.

Below is a broad overview of how to use the program.

Figure 4 illustrates the start-up page of the program after opening it from the computer start-up bar.

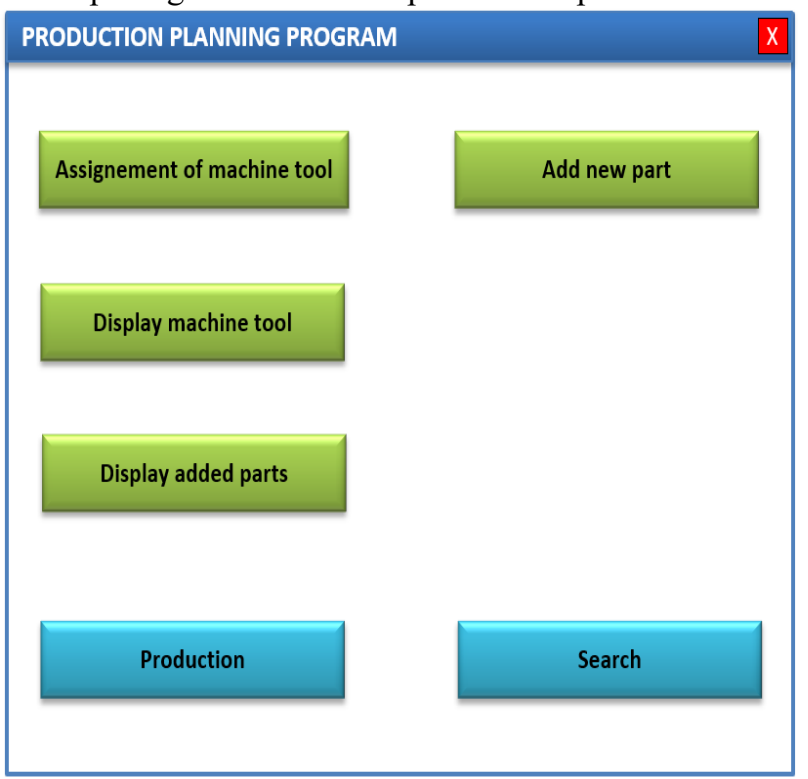

Fig. 4. Program start page

The Assignement of machine tool button opens the window where you enter the 3D model of the part and where the details about it are selected.

Loading the 3D model is done by activating the Search button in the newly opened window. In this way is named also the part, the name which will be used in the program. Some inputs are just to know the system from which the part is part of (project, line, station). The "Rh / Lh" box determines the amount of pieces needed to be manufactured. For example, if "Rh" or "Lh" is selected, only one piece will be processed. If " $\mathrm{Rh} / \mathrm{Lh}$ " is selected then two pieces will be processed, one of them will be symmetrical, and if "Rh=Lh" is selected then two identical pieces will be processed.

The type of part and its complexity must be known by the operator because these are the main factors in assigning the suitable machine tool. Machine tools are automatically selected based on their availability. For example, a part that can be machined on five machines, for it will be assigned the machine that has the shortest amount of time to complete the current processing. At the same time, the tools and devices available in a machine tool can determine its assignment.

After entering all part information, it can be seen a preliminary assignment of the machine tool, Figure 5.

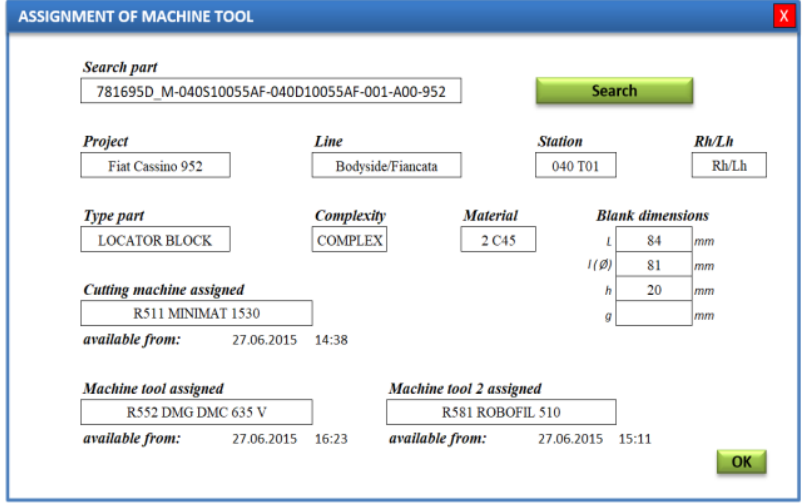

Fig. 5. Entering part information and preliminary view of assigned machine tool machines

If all the information is entered correctly, press the $\mathrm{OK}$ button and generate the file with the assigned machines, a file that is saved in the same location as the 3D model of the part. The program operator views the contents of this file, as illustrated in Figure 6.

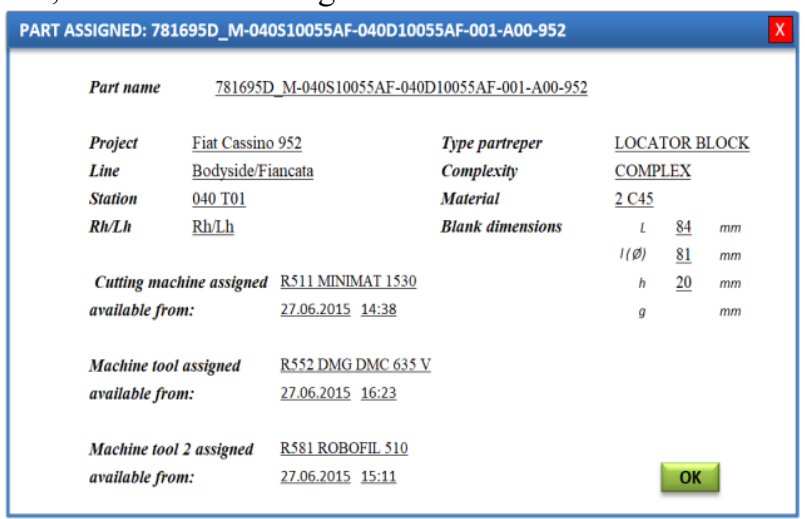

Fig. 6. Final view of machine tools assigned for the given part

The Add new part button opens the window where the CNC program of the given part is loaded. The file containing the CNC program is called "CNC- $x y$ " where " $x$ " is the CNC program number created and " $y$ " is the part name (Figure 7).

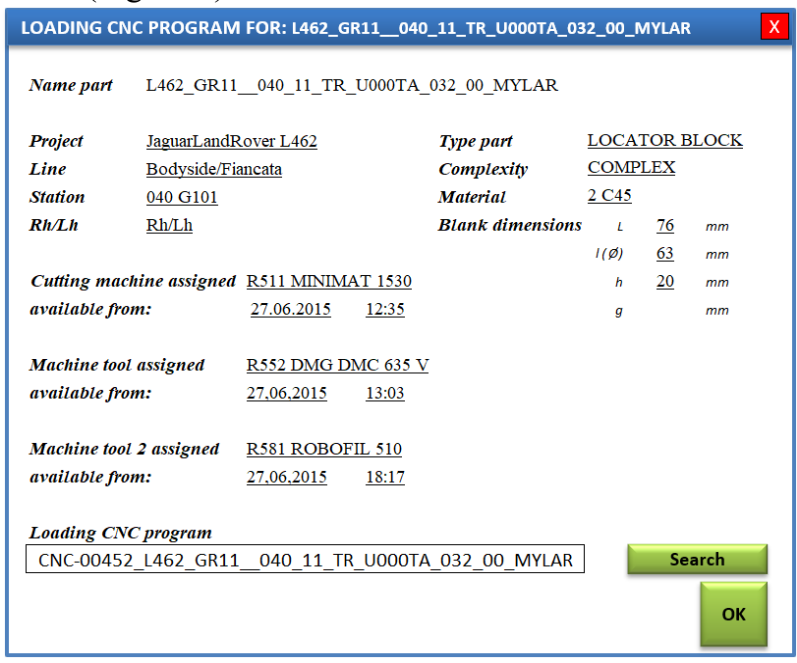

Fig. 7. Loading the $\mathrm{CNC}$ program for the given part 
The Display machine tool button opens the machine tool tracking window. Here are all the machine tools available in the mechanical processing site, which parts are processed, and which parts will be processed on these machines, their availability, their capacity, as shown in Figure 8.

A machine tool cannot be assigned for the machining of a part if its processing takes longer than the remaining time until the machine enters into maintenance. That's why each machine has an Activate / Deactivate button that stops it or starts it for various operations, either maintenance, repair or improvement by adding tools, devices.
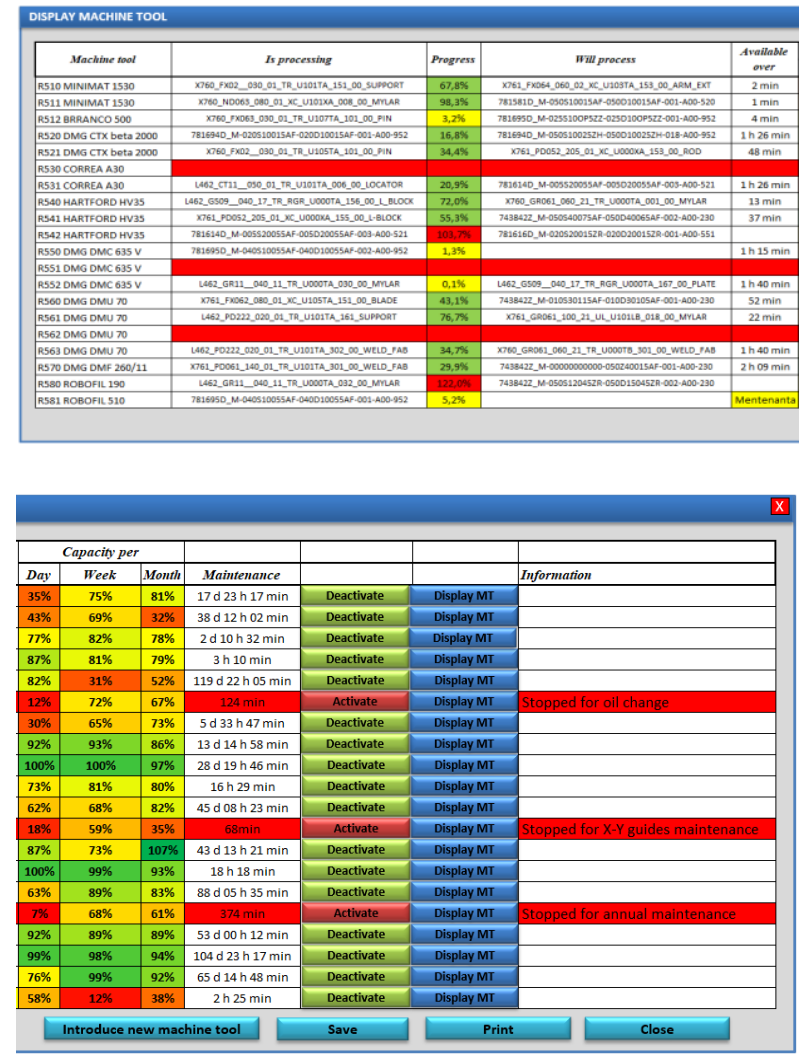

Fig. 8. Displaying the machine tools and the information about them

By pressing the Display MT button, it can be seen all details about the tool machine: the workpiece which is process on it, the workpiece which will be process, the available tools and devices, the machine capacity, the machine efficiency, etc.

The Display added parts button opens the window with the parts loaded in the program (Figure 9).

The parts can be processed on maximum 3 type of machine tools. In this window it can be seen which machine tools was assigned for the given part. The "Processing time" column contain the total time of processing part (in all phases: cutting, machining and electro-erosion) if the progress is $100 \%$ and the time spent until now if the progress is less than $100 \%$.

Pressing the Display part details button, a new window is opened where is displayed all information about the given part. Information like who have added this part in program or how much it cost, can be printed as a report file.

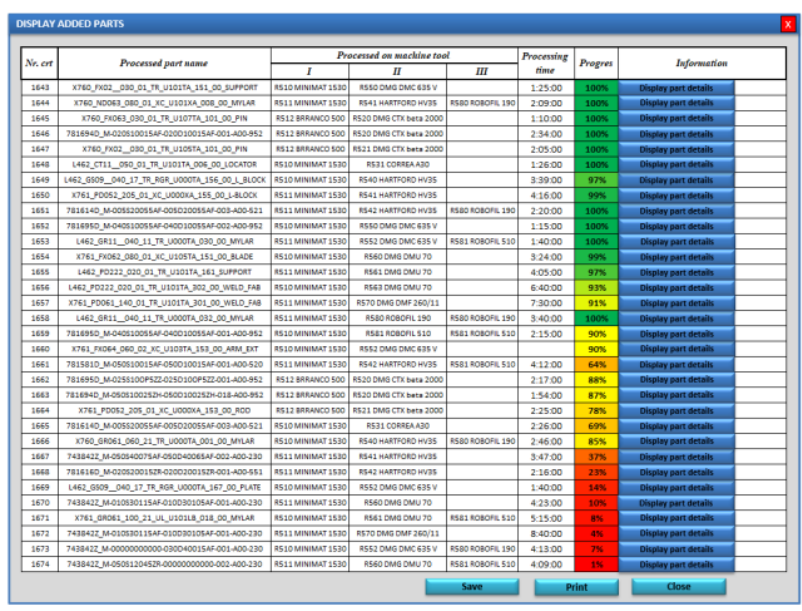

Fig. 9. Displaying the added parts in program and information about them

\section{Diagrams and graphs generated by the program}

The following figures show some examples of diagrams generated by the tracking and planning production program.

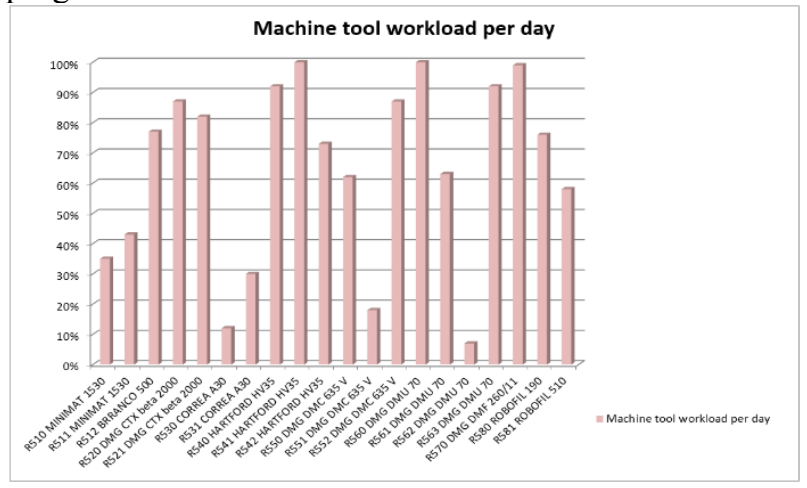

Fig. 10. Diagram of machine tool workload per day

As it can be seen from the daily workload diagram, Figure 10, some machine tools have a workload per day of $100 \%$. These machine tools are productively efficient because they work 24 hours a day.

The vast majority of machine tools have a workload between $50 \%$ and $80 \%$. These machine tools have an average workload that can be increased, but the fact that there are several machine tools of the same type can be considered that they have a good workload. The machine tools which have a low workload, such as the R530 CORREA A30 and the R562 DMGDMU 70, don't produce enough parts to be efficient.

Analysing this diagram, it is the decision to discover the elements that contribute to low efficiency. Some of the reasons may be: customer ordering of parts that can be produced on this machine is insufficient, the machine is in the maintenance or repair phase, the stages preceding the machining of the parts on these machines last longer than was planned.

For a better analyse of machine tools efficiency, is needed to see also the weekly and monthly workload diagrams, Figure 11 and 12. 


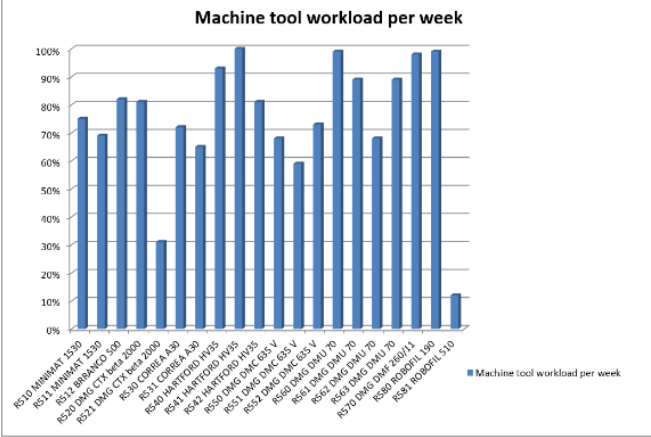

Fig. 11. Diagram of machine tool workload per week

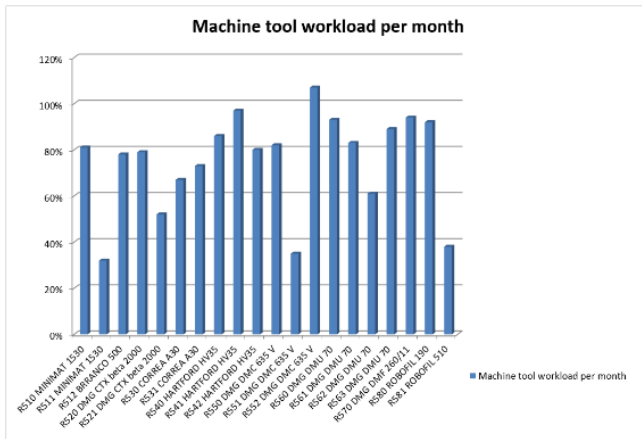

Fig. 12. Diagram of machine tool workload per month

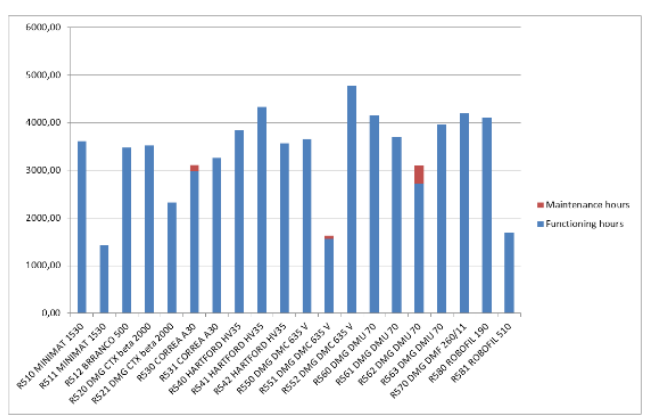

Fig. 13. Number of hours for functioning of machine tool and number of maintenance hours

If some machine tool has a lower workload per month is a disadvantage for production. This mean that this machine which was a cost for the company, now I not produce enough to amortize investment. If after the check, the machine is working in normal conditions, and is equipped properly for manufacturing specific part, is necessary to increase the order from clients. If not, it will be an extra cost for the company.

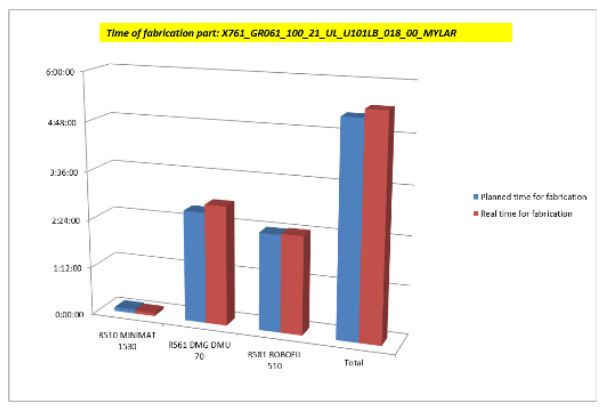

Fig. 14. Difference between the planned and real fabrication time for the given part on all machine tools where it is being processed

Another diagram provided by the tracking and planning production program, is the duration of mechanical fabrication for different parts diagram. This show how long time take the all operation to produce the specific part. The different operations are marked with separately colour to be more visible.

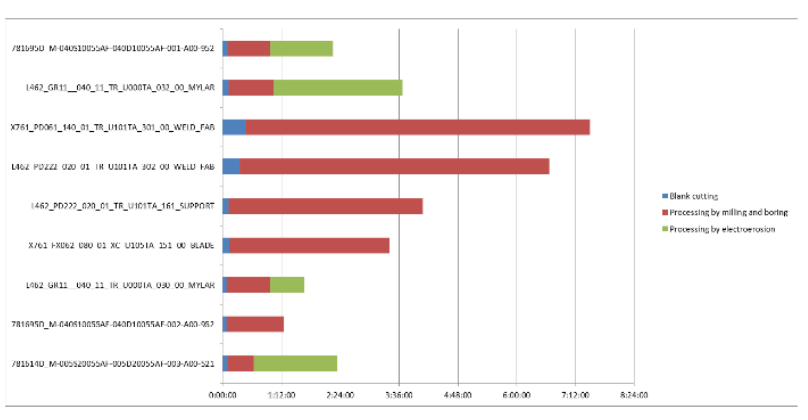

Fig. 15. Duration of mechanical fabrication for different parts, within 8 working hours

\section{Conclusions}

The program for tracking and planning production can be improved by changing the user interface in a more interactive way so that it is as easy to use. The program's databases must be as detailed as possible, to contain the correct information, which can be done by adding a procedure that checks all the information entered into the system.

With the increase in production capacity, this program needs to be adapted so that more users can enter, process, and save information in the system at the same time without affecting each other's work.

In conclusion, the program presented is appropriate to a manufacturing company's production by its simplicity of use, by generating reports on the actual situation in the department and by its efficiency in assigning machine tools suitable for processing the given parts.

\section{References}

1. H. P. Wiendahl, H. A. ElMaraghy, M.F. Zaeh, M. Kolakowski, Annals of the CIRP 56, 783-809 (2007)

2. E. Abele, J. Elzenheimer, T. Liebeck, T. Meyer, Reconfigurable manufacturing systems, Berlin : Springer, 3-13 (2006)

3. F. Jovane, E. Westkämper, D. Williams,Berlin : Springer, (2009)

4. S. V. Kumar, V. G. S. Mani, N. Devraj, Proc. Mat. Sci. 5, 1710-1715 (2014)

5. M. T. Tabucanon, B. Sasiwong, Applied Mathematical Modelling, 15, 3 (1991) 